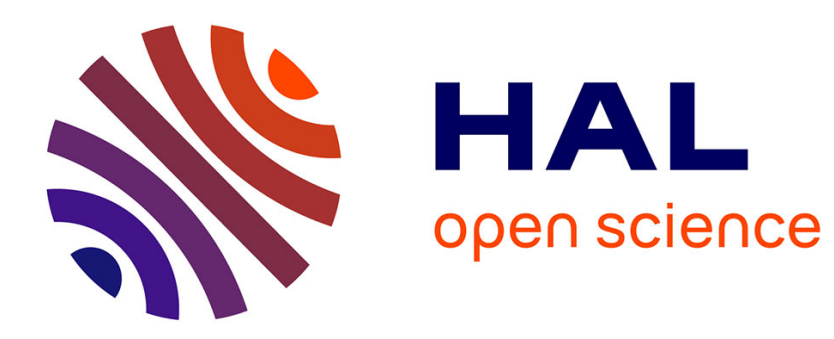

\title{
Material Ordering and the Care of Things
}

Jérôme Denis, David Pontille

\section{To cite this version:}

Jérôme Denis, David Pontille. Material Ordering and the Care of Things. Science, Technology, and Human Values, 2015, 40 (3), pp.338-367. 10.1177/0162243914553129 . halshs-01186728

\section{HAL Id: halshs-01186728 https://shs.hal.science/halshs-01186728}

Submitted on 25 Aug 2015

HAL is a multi-disciplinary open access archive for the deposit and dissemination of scientific research documents, whether they are published or not. The documents may come from teaching and research institutions in France or abroad, or from public or private research centers.
L'archive ouverte pluridisciplinaire HAL, est destinée au dépôt et à la diffusion de documents scientifiques de niveau recherche, publiés ou non, émanant des établissements d'enseignement et de recherche français ou étrangers, des laboratoires publics ou privés. 


\title{
Material Ordering and the Care of Things
}

\author{
Jérôme Denis \\ LTCI - Département Sciences Économiques et Sociales \\ (UMR 5141) CNRS - Telecom ParisTech \\ jerome.denis@telecom-paristech.fr
}

David Pontille

Centre de Sociologie de I'Innovation (UMR 7185) CNRS - Mines ParisTech david.pontille@mines-paristech.fr 


\begin{abstract}
Drawing on an ethnographic study of the installation and maintenance of Paris subway wayfinding system, this article attempts to discuss and specify previous claims that highlight stability and immutability as crucial aspects of material ordering processes. Though in designers' productions (such as guidelines or graphic manuals), subway signs have been standardized and their consistency has been invested in to stabilize riders' environment, they appear as fragile and transforming entities in the hands of maintenance workers. These two situated accounts are neither opposite nor paradoxical: they enact different versions of subway signs, the stabilization of which goes through the acknowledgment of their vulnerability. Practices that deal with material fragility are at the center of what we propose, following Annemarie Mol and Maria Puig de la Bellacasa, to term a care of things. Foregrounding such a care of things is a way to surface a largely overlooked dimension of material ordering and to renew how maintainability issues are generally tackled.
\end{abstract}

\title{
Keywords
}

Care $\cdot$ Maintenance $\cdot$ Material Ecology $\bullet$ Material Vulnerability $\cdot$ Ordering Devices 
It is as though our material involvement begins only when the stucco has already hardened on the house front or the ink already dried on the page. We see the building and not the plaster of its walls, the words and not the ink with which they were written. In reality, of course, the materials are still there and continue to mingle and react as they have always done, forever threatening the things they comprise with dissolution or even "dematerialization" (Ingold 2007, 9)

One day in 2007, in the workrooms of a technical department of the Régie Autonome des Transports Parisiens (RATP), the Paris transportation carrier, a passerby could stumble upon the following scene (figure 1): a directional sign, partly damaged, sticking partway out of a garbage can. Such an image would be nothing new for the workers who walk the RATP's hallways, who come across signage elements in different shapes, states, and conditions each day. But for someone who knows the role that objects play in Science and Technology Studies (STS), it is worth taking a moment here to examine this particular scene. Signs can be seen as crucial elements in urban assemblages (Farías and Bender 2010). Wayfinding systems are generally considered one of the numerous sociotechnical entities that shape the city (Latour and Hermant 1998), supporting specific modes of ordering that perform and maintain "spaces of flows" (Knox et al. 2008). Part of the numerous "immobile infrastructures" dedicated to mobility (Urry 2007, 19), signs have also been analyzed as powerful disciplinary devices that order spaces through the partial control of users' bodies (Ureta 2012).

These claims and the scientific perspective they bear witness to contrast strongly with the image of the board sticking out of the trash bin, far from the ordering processes the signs supposedly participate in. What should we do with this scene? How should we take account of this precise object's mode of existence? Should we retain only the fact that it no longer responds to the felicity conditions necessary for its performativity: neither in good shape, nor in the "right place" (Latour and Hermant 1998)? Should we consider it no longer as a sign but rather as a deteriorated object, now a piece of rubbish (Thompson 1979)? Rather, can it teach us something about material ordering processes, about the ordinary life of these types of objects, and about the role of the people in charge of them? 
Figure 1. A signboard in a trash bin

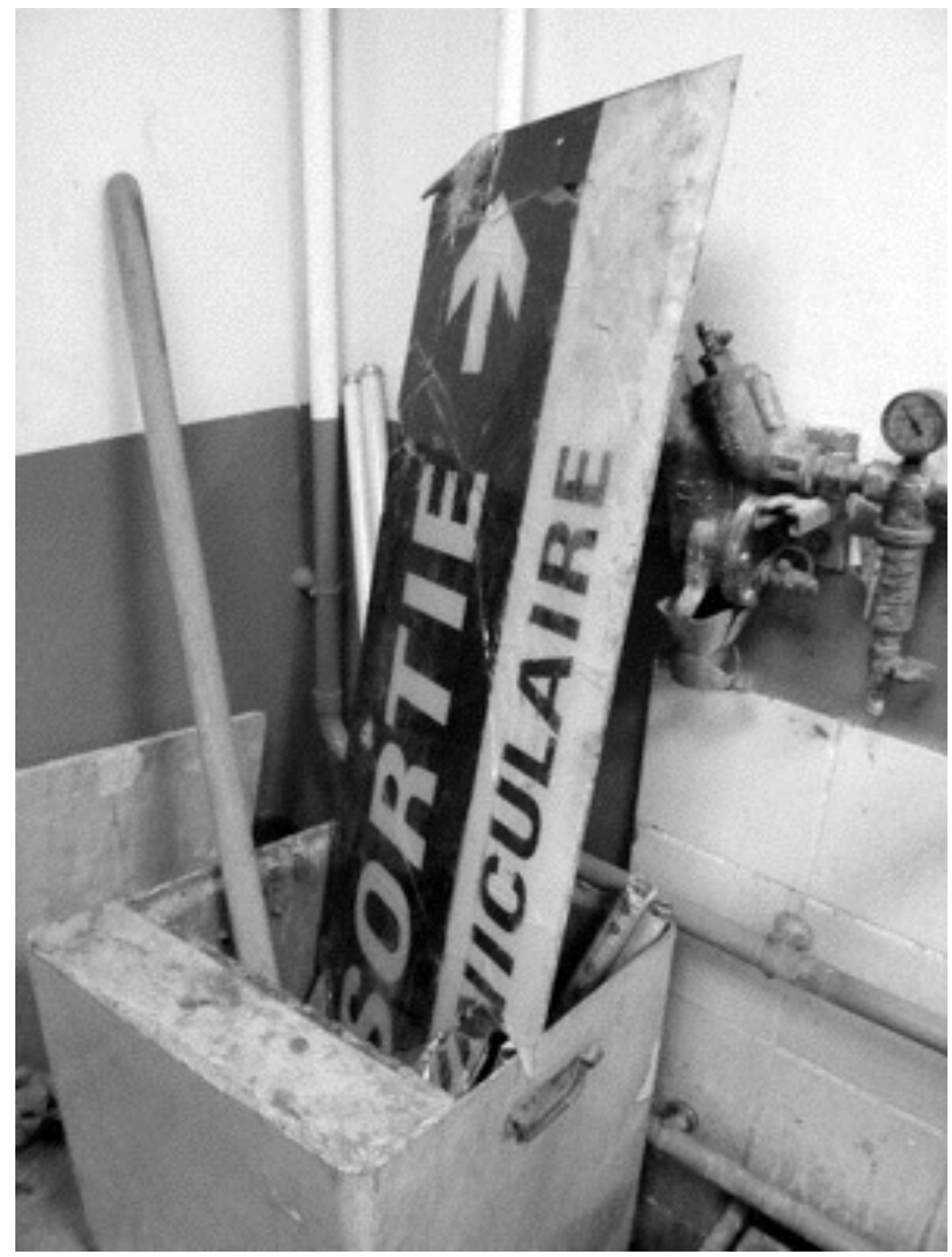

In this article, we would like to explore this last option and to do so we will examine two aspects of the sign, as both a stabilization and ordering device and as a fragile object. In linking the image of the discarded board to the work needed to guarantee the Paris wayfinding system's existence through time, we aim to show the strong ties between these two aspects of the signboards as well as the role played by repair and maintenance (Henke 2000; Graham \& Thrift 2007) in their articulation. Our goal is to pursue discussions on nonhuman agency and artifact performativity (Latour 1996; Knorr-Cetina 1997; Pels et al. 2002) and particularly on the role played by objects in the production of sociomaterial order (Winner 1986; Verbeek 2004).

More generally speaking, the question of the vulnerability of objects is a means of questioning how the social sciences, in the wake of scholars such as Barad (2003), Bennet (2004), Orlikowski (2007), Law (2010), Suchman (2011), treat the material dimension of society and the place occupied by matter in our everyday lives. We will show why it is productive to consider the material aspects of social order, all the while refusing to reduce matter to properties such as solidity and durability. Fragility is a mode of existence of matter 
that must be considered if material ordering processes are to be documented in their full complexity.

In order to bring these two aspects of objects together into a single analysis, we will draw upon post-Actor-Network Theory studies (Law and Hassard 1999; Gad and Jensen 2010) and in particular Mol's ontological politics (Mol and Law 1994; Mol 1999). Following these scholars, we can assume that there are two versions of subway signs. In their first version, subway signs are stabilized. They are apprehended as standardized graphic objects that make the Paris subway wayfinding system solid and immutable. In their second version, these same objects are apprehended as vulnerable. As they are worn down, broken, and even disappear, they appear fragile and mutable.

An important issue is the articulation of these two versions, accomplished mainly through maintenance and repair as processes dedicated to restoring order (Brand 1994; Henke 2000; Graham et Thrift 2007; Gregson et al. 2009; Edensor 2011; Jackson 2014)1. Essential elements in the ongoing production of sociomaterial order, maintenance practices draw on forms of engagement with material objects that are largely overlooked. In analyzing these forms of engagement, we will be able to show that maintenance work participates in a care of things that, like other care practices (Mol, Mozer and Pols 2010), has yet to be explored. This care of things reverses the traditional view of the role of artifacts in society in that it concentrates on the material fragility of things and the constant necessity of taking care of them.

\section{Subway Signs in Paris: Investigating Design and Maintenance Practices}

Between March 2007 and March 2008, we carried out an ethnographic study on the Paris subway signage system. Unlike much research on wayfinding systems (Sharrock and Anderson 1979; Timpf 2002; Vertesi 2008), this study was not focused on user practices nor on how signs are mobilized in situation, but rather on the installation of a new wayfinding system and its daily preservation (Denis and Pontille 2010a)

In our investigations, we first looked to identify the main guiding principles of the signage policy and their ensuing work organization processes. We conducted thorough interviews with RATP employees from the signage design and normalization departments. From these interviews emerged two types of material: spoken discourse about particular key moments in the history of the new wayfinding system, and detailed descriptions of the concepts, assumptions, and tools that shaped the production of this particular signage system.

Among the RATP archives, we systematically gathered internal documents (minutes from the Administrative Council meetings, spec sheets, press material, internal media documents) as well as files, still applicable, from the conception and normalization department (graphic standards manuals, informational leaflets, slides from an internal presentation announcing

\footnotetext{
1 Here, we investigate a specific form of maintenance that differs from recycling, which generally extends the social life of things by modifying them (Thompson 1979; Appadurai 1986; Engestrom and Blackler 2005).
} 
the new signage system, articles from internal journals, subway guides, reports on rider satisfaction and service quality). These documents were useful in understanding the strategic dimension attributed to the signage system, as well as the precise terms of its installation and application.

Finally, we spent several weeks observing the signage maintenance department. Such observation took place in the department offices, the workspaces where certain signs were manufactured, and in the subway stations themselves, where we accompanied pairs of workers on numerous rounds made in order to repair or replace signs in the subway network. With the help of our fieldwork notes, audio recordings and photographs, we have attempted to grasp, to the greatest extent possible, the ecology of these maintenance interventions. This includes the major steps of the work process, the tools used and the actions carried out as well as the hesitations and discussions on the part of the agents at work. The observations were complemented by an analysis of the documents associated with the maintenance work (forms, work orders, intranet site, etc.) and by interviews with department managers.

\section{Stabilization}

In Paris, subway signs became a matter of reflection and discussion within the RATP at the beginning of the 1990s. At this time, the carrier was involved in important transformations: the creation of an automated, driverless subway line and a politics of complete renovation of the spaces dedicated to riders (Joseph 2004). A few employees made a plea for a radical rethinking of the wayfinding system and won their case under such circumstances of great organizational upheaval favoring audacity. They built a multidisciplinary team of specialists (graphic designers, cartographers, and architects) to conduct the project. This team carried out various surveys, field studies, and experiments, which eventually resulted in the design of a complete wayfinding system and the writing of a particularly ambitious policy.

At the origin of this large-scale project was the harsh diagnosis its initiators made about the existing subway signs, which were mainly stigmatized as being too variable from one part of the network to the other. The complete overhaul the designers urged was thought of as a solution to what they considered the real failure: semiotic diversity.

We stated the fact that our ways of writing things and displaying them was really heterogeneous. And it really was a big deal. Visually it was pretty obvious. Because there were different places that were linked, but also because in the same place, we would find different styles of signboards... (Interview August 3, 2007, former member of the design team)

The struggle against heterogeneity was considered as a means to strengthen the wayfinding system and invest in subway signs as ordering artifacts. Such a struggle led to a strategy of stabilization, which was organized around two main points: the spreading of signboards all over the transportation network and the standardization of its constituent elements. 


\section{Spreading}

The new policy basically generalized the signage itself, initiating a first and crucial move: the adoption of a consistent system for the entire Paris transportation network, or, in the terms of the RATP, a system based on 'multimodality'. Before the 1990's, each mode of transportation had its own particular signage system with its own typographical identity. Bus signage was written in Helvetica, regional train signage in Formula One and subway signage in Metro (a specific version of Univers designed by A. Frutiger). Each of these systems had its own arrows, set of colors and layout. The new wayfinding system was conceived as a means to remedy these differences. The same set of signs was designed and implemented all over the transportation network and for every modes of transport: subway, regional train, bus, tramway, etc. Such homogenization was not conducted for the sake of aesthetic convictions only: setting up a multimodal wayfinding system sustained a certain definition of transportation services entirely oriented toward rider comfort.

A single network of signs... a single language on all the lines of the network. In the morning on the subway, in the afternoon by bus, the day after by regional train... The user freely rides all of the RATP's modes of transportation, and the signs that guide her different journeys must remain the same. Their assimilation shall gradually facilitate the user's rides and, furthermore, make her experience the complementarity of the different modes of transport. ( $A$ multimodal wayfinding system, RATP 1997, 2)

In parallel to the graphical harmonization between modes of transportation, the new signage policy dramatically multiplied the occurrences of signage components: many more signboards occupied much more space within the network. The designers wanted to equip each junction, corridor, hall, stairwell, and platform with signs in order to provide as many indications as possible. This led to the creation of a great number of boards, meaning that the constituent elements of signage would be displayed in many places. The designers' aim was to help riders along every step of their journey, providing a real "Ariadne's thread" (Wiart, Le Roux and Lomazzi 1998) that would prevent them from ever getting lost.

Telling everything, everywhere and all the time. (...) Regardless of the location, signage is endlessly repeated and in different formats, but always perfectly the same, according to the established rules. Repetition creates unity, promotes recognition, and enhances the comfort of the riders. (A multimodal wayfinding system, RATP 1997, 5)

An extended graphical layer had therefore been put in place, covering walls with arrows, destination names, line numbers, and so forth. Such omnipresence of signs - and this remains one of the specificities of the Paris subway system - radically transformed the transportation spaces. It performed a hybrid environment which was no longer merely architectural and where "the distinction between the building and its signs, between the text and the territory, [became] indistinct" (Fuller 2002, 236). Since then, the Paris subway network has been populated by countless signboards that remain the same from one mode of transportation to another: it offers a seamless semiotic environment, a literal graphical infrastructure meant to equip mobility practices and guide riders in every nook (Denis and Pontille 2010b). 


\section{Standardization}

These two principles, multimodality and omnipresence, were actualized through a large-scale standardization policy, which deeply changed the role of subway signs in the ordering process. The RATP's previous wayfinding system policies could be laid out in few documents and were transmitted or recalled orally. When it came time to change a board or get a new one, someone would provide more or less detailed advice. For the first time in the history of Paris subway signs, the new wayfinding system policy was made up of numerous and precise rules, detailed in voluminous graphic standards manuals. Extremely accurate instructions about the shape, colors, layout, materials, or emplacement of each kind of boards could be found in these documents.

The standardization process has had effects on various levels. For instance, the spacing between signboards components has been normalized (figure 2) as well as the shape of arrows and their possible directions, which have been restricted to eight. The colors displayed on the boards have been subject to specific treatment. There are now no more than twenty-seven colors, and they have been systematically assigned to certain transportation lines (subway, tramway, regional trains), but also to particular types of information (e.g. white backgrounds for connections, blue for exits, gray for services, brown for tourist information). Their colorimetric characteristics have been set (reflectance values and curve, trichromatic components, CIE Lab coordinates, supplier reference, and the required quantity of each coloring agent) for each coloring technique (painting, flat offset, quadricolor offset, serigraphy, enamel). These extremely detailed specifications are important means of homogenization: they allow colors, which are highly unstable phenomena, to remain the "same" from one wayfinding unit to another, recognizable in every area of the network.

Figure 2. Example of standardized graphic composition (Graphic standards manual vol.3, RATP 2007b)

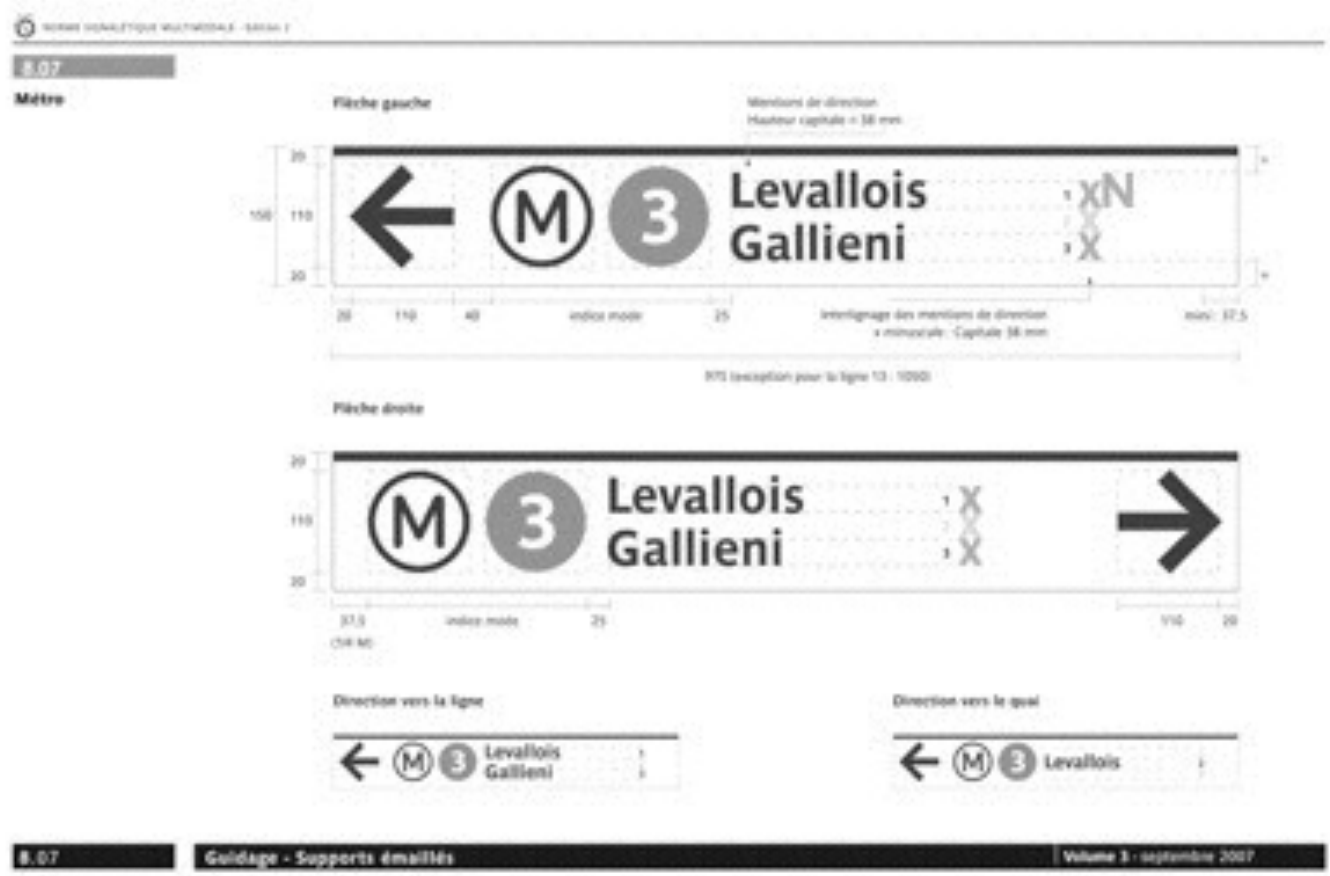


Standardization has not been restricted to layout. The emplacement of signboards within subway spaces has also been precisely delimited. Their very size has been normalized and aligned to the dimensions of the tiles found on the walls of every station. Moreover, very detailed rules of emplacement have been established for each situation, which makes it possible, for instance, to define the direction of arrows on boards according to their position. Linguistic content itself has been the object of standardization. The signage designers created what they called a "visual language" using a series of normalized pictograms that crystallize instructions and descriptions in small graphical components, which can be articulated into units and reused all over the network. Strict guidelines have been set on words themselves and their uses: for example, abbreviations have been codified into a list that gives the proper shortened form of each common word (figure 3).

Figure 3. Abbreviations (Graphic standards manual vol.2, RATP 2007b)

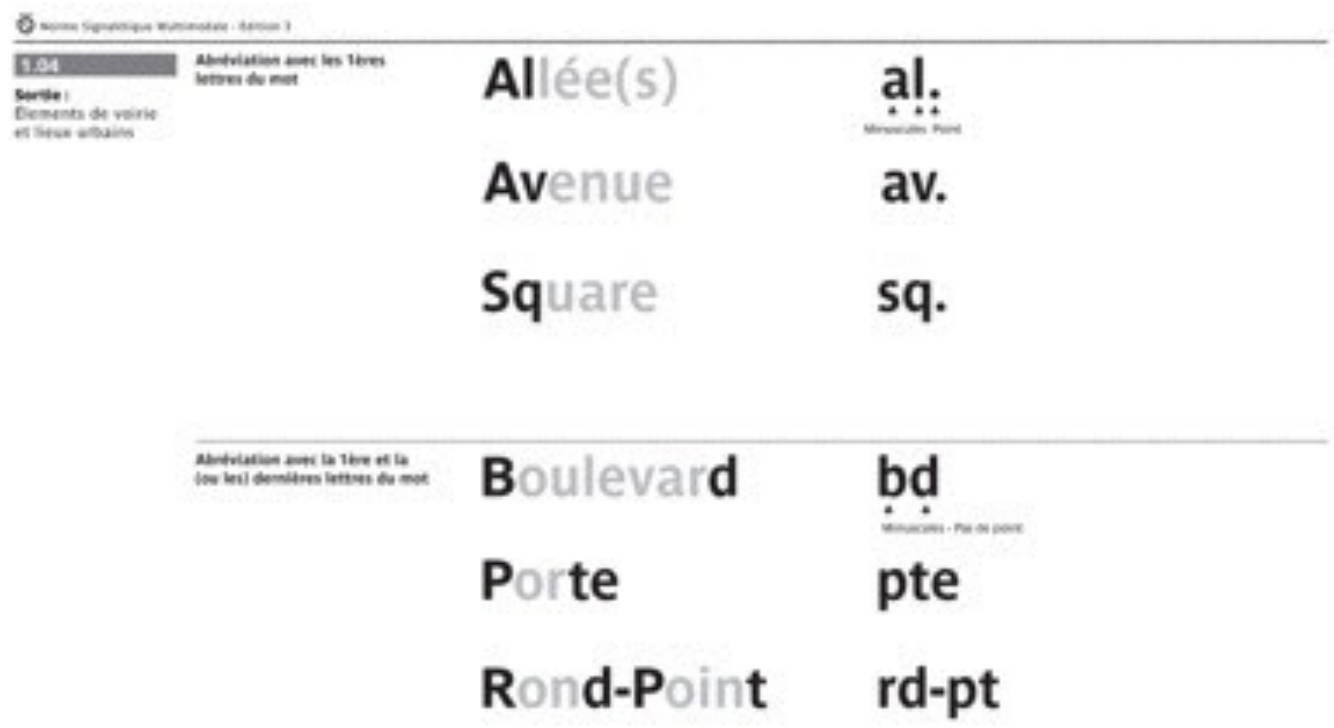

In addition to the list's functional words, some names were also affected by the standardization policy, in particular those that designate public places. Indeed, though one may think that there is an official denomination, defined once and for all for well-known sites, in reality public names continue to change and multiply in their common uses. For instance, in France, the airport in the north of Paris is named in a number of ways: Charles de Gaulle, Roissy-Charles-de-Gaulle, CDG, or just Roissy... Names like these are never completely normalized and their forms vary. Such variety was an important matter of concern in the eyes of the signage system designers. Within the wayfinding standardization policy, names not only needed to remain unchanged, but they also had to be concise and easily recognizable.

The name used to indicate a place has to be as short as possible, and close to everyday language. Therefore, official designation will not be systematically taken up. (For instance: "Centre Georges Pompidou" instead of "Centre National d'Art et de Culture Georges Pompidou”). (Riders Information Guide, RATP 2007a, 22) 
With such normalization, public names have been solidified, turned as much as possible into "rigid designators" (Kripke 1980). Their articulation with the other wayfinding system components also has been reinforced. Stabilized, they became just as functional as arrows, pictograms and line numbers, thereby integrating the modular language conceived by the designers into the system as a whole.

What did designers actually do with such a policy? Struggling against semiotic heterogeneity, they aimed at an ambitious reordering of signage constituent elements, which they saw as an essential operator for the intelligibility and efficiency of the riders' environment. This reordering process took the form of harmonization and standardization. In other terms, designers invested in fixity and consistency as a means for material ordering.

The role of materials stabilization is a well-known argument in STS, notably in the case of inscriptions. From Goody's "literate technology" (Goody, Cole and Scribner 1977) and Eisenstein's "typographic fixity" (Eisenstein 1983) to Latour's "immutable mobiles" (Latour 1986), physical stability is regularly analyzed as an essential aspect of written object agency. In the Paris wayfinding system, subway signs have been mandated to maintain order not only as immutable artifacts, but also as immobile ones. For the wayfinding system to be a reliable feature of the transportation services, designers assumed that subway signs would need to remain constantly in place. The subway signs were, as such, designed as immutable immobiles.

Such an account draws a first version of the Paris wayfinding system, where material ordering lies in the shaping of a consistent and stabilized semiotic apparatus. This version fits perfectly with an almost canonical framework in STS. However, we can still wonder, following Law (2004), what do we miss if we endorse and accept this version completely? Which aspects of the wayfinding system remain out of the picture? Crucial to this version is its staging of subway signs in a particular state. Such a version applies easily to brand-new signboards, fresh from the factory and just put up. But then, are we sure they remain exactly in this state? What happens to signboards, far away from guidelines and standard specifications? How do they manage to remain in place and unchanged? How is their performativity preserved "in the wild"?

\section{Vulnerabilities}

Shadowing maintenance workers is a useful way to discover another mode of existence of technical objects that we are rarely aware of as users and which designers themselves largely ignore (Orr 1996 ; Denis and Pontille 2010c). In the first version, maintenance workers are not in the picture. They are part of the army of invisible workers cherished by S.L. Star $(1995,3)$ : the ones who "do the dishes and take care of garbage", the ones who deal with the dirty and messy side of mundane situations. In the Paris subway system, five men were in charge of signboard repair and maintenance at the time of our study. They were part of a maintenance department where other workers were tasked with manufacturing PVC boards. Day after day, they repaired damaged signboards, cleaned dirty ones, removed obsolete others, and brought new ones from the workshop... In doing so, they dealt not with trivial side issues, peripheral to what subway signs "really" are. Rather, they experienced 
another version of subway signs in dramatic contrast to the previous one: this second version takes fragility as an essential feature and prompts us to question the heterogeneous material ecology involved in the performativity of artifacts.

\section{Fragility}

One of the things that struck us as we were following maintenance workers, especially after interviewing designers and studying guidelines, was the very vulnerability of the subway signs displayed in the stations. Walking through corridors and platforms with the maintenance workers, we encountered signboards in very different states and became aware of both the significance and the plurality of their fragility. During some interventions, for example, we dealt with signboards that had to be replaced because their colors had faded, or because they were worn out. We saw other boards whose surface had been attacked by mold, which reminded us that some Paris stations are situated near the Seine River and are prone to serious leakage problems (figure 4). Besides wear and tear, maintenance operations are also concerned with acts of violence directly targeted at the signboards. We discovered that, along with the usual tags and graffiti, signboards could also receive blows that smash all or part of their surface. This is a less known aspect of "public lettering" studied by Petrucci (1993), who focused on the design of specific inscriptions as an instrument of public power and mainly emphasized the issues of emplacement, visibility and legibility. The display of writing in public settings also implies its exposure to numerous dangers. Because of its very publicity, public lettering is fragile lettering.

Figure 4. Mold on a signboard

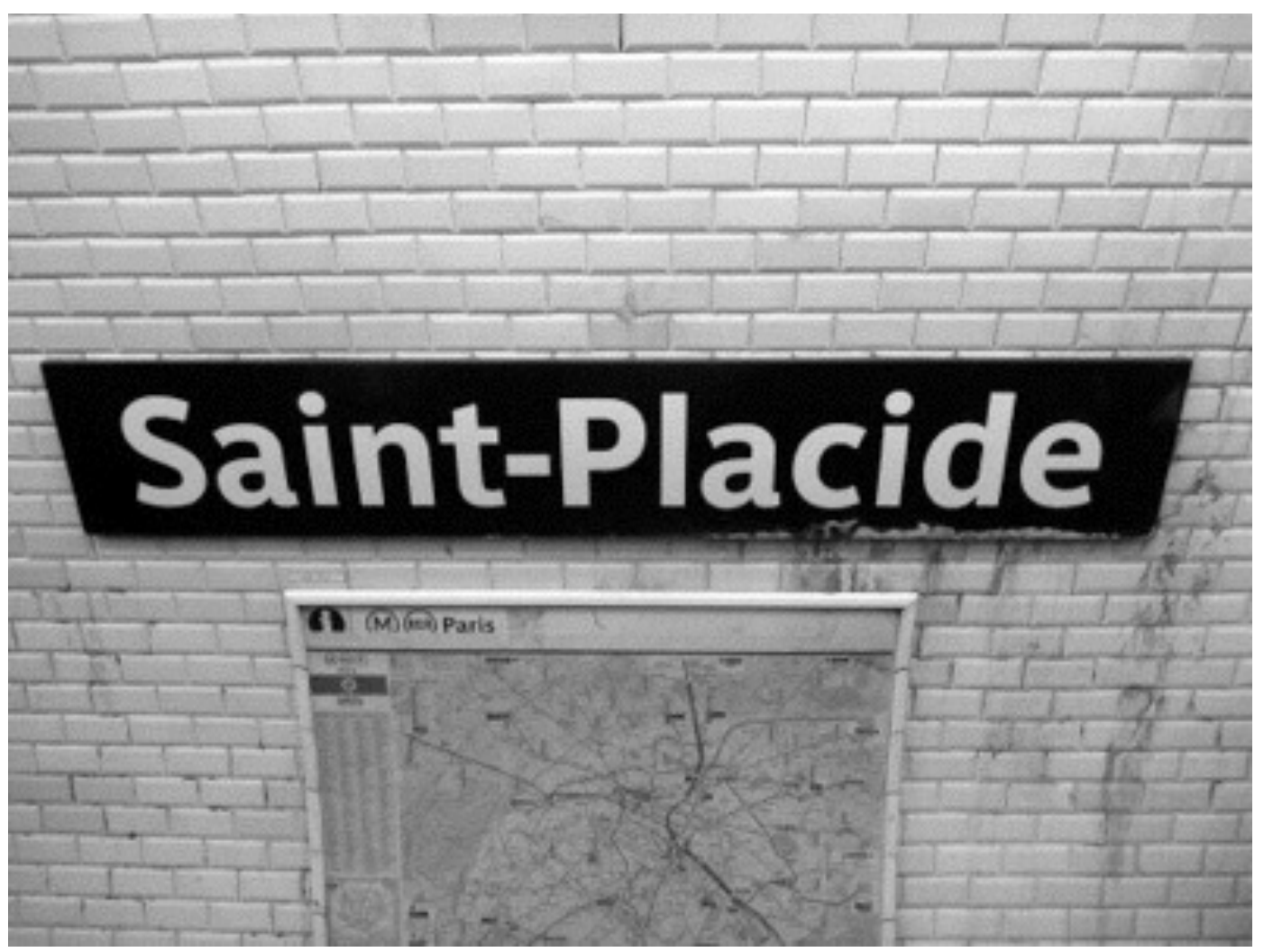

We were also confronted with the fact that signboards could have a much more turbulent life than imagined initially. Far from being condemned to immobility, some of them do actually 
circulate and leave subway spaces. Indeed, subway signs can be coveted so much that sometimes they get stolen (by collectors, resellers, or simply by people who want to decorate their apartment). Such a disappearance marks a transition in the life of signboards (Thompson 1979), which become commodities and enter "into the sphere of circulation and exchange" (Engestrom and Blackler 2005, 319). And this is a transition that represents a significant danger for a wayfinding system that relies on the omnipresence of signs.

Here, subway signs are no longer either immutable or immobile. During their daily rounds, maintenance workers deal with changing signboards, facing one mutation after another. These transformations, which occur in corridors, halls, and platforms, contrast starkly with the homogenization policy and show that the wayfinding components have not been stabilized once and for all. Because each signboard is vulnerable, it is a potential weak link in the network, an evidence of material variability that represents a not negligible threat. Tiny though the mutations are, they endanger the integrity of the whole system.

More generally, subway signs no longer play the part that had been ascribed to them by the designers. Maintenance workers do not handle boards as stabilized objects whose material properties would be "tangible resources that provide people with the ability to do old things in new ways and to do things they could not do before" (Leonardi and Barley 2008,161). In their hands and eyes, materiality rhymes with fragility and material properties are sources of worries. Such worries imply a specific form of engagement with objects, and the maintenance workers develop an acute attention towards wayfinding system components. In fact, none of their diagnoses is obvious. Mutations and the ways they occur cannot be completely known in advance, and supervision of the wayfinding system is not a mechanical activity that would consist in taking inventory of predefined deviations from the standard. When entering subway stations, maintenance workers conduct inquiries (Dewey 1938/1991) through which they treat signboards not as single things ordered in settled form, but as part of a complex material ecology.

\section{Material Ecology}

In a paper debating material culture studies, Ingold (2007) suggests a radical rethinking of the way scholars traditionally deal with matter. In particular, he urges an abandonment of the very notion of materiality in order to fully explore the diversity of materials, their relationships, and their mutations.

It seemed to me that the concept of materiality, whatever it might mean, has become a real obstacle to sensible enquiry into materials, their transformations and affordances. (Ingold 2007, 12)

In taking this position, Ingold looks to prevent researchers from taking what he considers to be a restrictive, if not risky, perspective focusing on the materiality of isolated artifacts. He insists that this approach has hardly anything to say about the "stuff that things are made of," that indeed it is limited to providing abstract and narrow analyses of objects already made, which are sometimes even considered as passive containers of external social forces. The other problem is that, in any case, it consists in distinguishing another side of reality that would be immaterial by default. To Ingold, such an approach precisely misses what it seeks 
to grasp by reducing material to aspects such as tangibility and inertia. Instead, the properties of materials, Ingold emphasizes, are not fixed attributes of matter but are processual and relational. His argument is in line with the posthumanist performativity proposed by Barad (2003) that considers matter as an active participant in the iterative process of the world's becoming. Matter is neither a given resource nor a mere effect of human action. Rather, materials move, transform, damage, mutate, form alliances in a more or less durable way and are constitutive parts of animated things called humans, made of water, bones, blood, hair... As "the protean source of being" and "energetic forces" (Bennet 2004), they are essential features of human agency.

This position against some of material culture studies, which defends an analysis of situated material ecologies, may appear as a highly theoretical part of an esoteric debate (about humanism, vitalism, organicism) restricted to specialists in metaphysics. But it is completely grounded in concrete issues and plays a crucial part in the course of the ordinary actions of maintenance workers. Whereas "materiality" does not mean anything to them at all, the life of material entanglements and signboards are, on the contrary, part and parcel of their daily concerns.

Before leaving the maintenance department, Brian and Jonathan ask for metal brackets from the shop manager, explaining "the last time we had to take the board down because it was about to fall out. It rested on small pieces of rotten wood, and it was highly dangerous..." Once the van is parked in front of the station, they stay inside preparing and drilling holes into the brackets. After entering the subway station, they set up without hesitation in front of an empty wall displaying some traces, giving clues about the previous presence of a signboard. They remove the old screws so that the metal brackets will hold correctly on the wall: "they've been here for sixty years!" says Brian. Jonathan goes right ahead, tearing away all the screws he can and breaking down the rest: "what matters is that nothing juts out above the wall." When the wall is ready, they measure both board and brackets, and scribble a few marks on the wall. They use the tiles as a guide to make sure the new board will be positioned straight. Brian starts to drill into the wall at the appropriate places. Jonathan decides to fill holes with some glue cement and places the plugs in it. Then, they set up the first metal bracket, put the signboard up, and begin to mark the position of the second metal bracket. (September 7, 2007, Fieldnotes)

This intervention shows that the material dimension of maintenance work is not univocal. The maintenance workers encounter several kinds of materials located on multiple layers: the wall (itself made of tiles, the glue that holds them, and the plaster they lay upon), the metal brackets, and the signboard. Their work consists in considering these different material sites, strengthening their composition according to their own criteria, and making them hold as a coherent assemblage with the help of other materials: glue cement, plugs, and screws. Throughout the intervention, which goes from the workshop where the metal brackets are made, to the workbench in the van where the holes are drilled, and all the way to the subway station, the boundaries of things remain blurred ${ }^{2}$. The maintenance workers are immersed in

\footnotetext{
2 This intervention also highlights that the environment itself (wood, walls...) is fragile and mutable. Material vulnerability concerns every kind of objects and situations like the scene above shows that the interdependencies between things and their environment can include fragility.
} 
a malleable material flux. In this flux, they neither mobilize nor rely on the "materiality" of signboards: they deal with distinct material properties, which they discover and explore in the course of action.

In this respect, they do not use their hands only. They also rely on tools, whose manipulation underlines other forms of material interdependence.

While Brian is ready to set up the second metal bracket, he feels the power of the drill weakening. The battery has run down and Jonathan gets impatient: they cannot leave the wall in such a state. Brian goes upstairs to the van, hoping to find another drill. He comes back disappointed: the second battery has also run out. After some hesitations, the maintenance workers agree to take a break and leave the tool to charge in the station. Then, they go in search of the technical premises. On arriving, they plug the tool into the battery charger and leave the station in the direction of the nearest staff canteen. They are back one hour later. The battery is not fully recharged but its power is sufficient to handle the last operations needed to put the signboard in appropriately. (September 7, 2007, Fieldnotes)

This latest episode is trivial and well known by users of battery-operated power tools. Yet, it sheds light on a crucial dimension of maintenance activities. The tools that help maintenance workers in repairing signboards link them to a complex network of infrastructures. Usually transparent, this network complicates each intervention when any kind of failure occurs (Star and Ruhleder 1996). Such interdependence between devices constitutes an essential feature of the material ecology that characterizes repair and maintenance work (Graham and Thrift 2007).

This second account dramatically contrasts with the previous one. It foregrounds what was kept invisible in our first version of the Paris wayfinding system: the heterogeneity of the environment, the fragility of signboards, and the numerous operations that deal with this fragility. In other terms, what we do miss with a story that focuses on the standardization policy and stabilization processes is mess (Law 2004), and the worries that go with it. Will the glue hold? Should the concrete be covered? Will we be able to remove these screws? How dry is the plaster? In the hands of the maintenance workers, signboards are unsteady objects, and their interventions are more a matter of entangled material agencies (Barad 2003; Edensor 2011) than of homogenized components in a stabilized environment. Heterogeneity and disorder, two issues that were supposedly covered by standards and guidelines, are indeed at the core of their work.

But does this new version invalidate our first account of the Paris subway wayfinding system? Does it mean that subway signs have nothing to do with ordering processes? Does it mean that their immutability and immobility are just an illusion? Not necessarily. We can instead accept to break with a definition of material order as a "once and for all" stabilized state and recognize the importance of maintenance work in the ceaseless performance of a stabilized world (Henke 2000; Graham and Thrift 2007; Weisman 2007; Edensor 2011).

\section{Mess and Enacted Order}

Social scientists have known for a long time that order and disorder go hand in hand. Order does not get rid of disorder, just as bringing disorder to light does not remove order. This is a 
crucial point for the first laboratory studies that investigated the concrete conditions of the production of scientific facts: "It is also part of our world view that only from disorder can an orderly pattern emerge... The construction of order relies upon the existence of disorder" (Latour and Woolgar 1986: p. 251). In the sciences, order is performed with immense difficulty and at a very significant cost. In the case of maintenance activities, producing order is less costly, but necessitates operations that have a short reach, like the "negotiated order" observed by Strauss (1978) in organizations, and situations of "remedial interchange" described by Goffman (1971). The emergence of order from disorder in maintenance work is always ephemeral. It draws on situated reordering micro-processes that have to be continually repeated. The very stability of the wayfinding system relies on each of the maintenance workers' interventions.

And if things seem solid, prior, independent, definite and single then perhaps this is because they are being enacted, and re-enacted, and re-enacted, in practices. (Law 2004, 56)

The maintenance workers deal with the uncertainty and fuzziness of more or less stable material assemblages. Repairing or replacing a signboard is a precarious affair that participates in the general continued stability of the wayfinding system. Sometimes, moments of restored stability are particularly obvious. In the scene we described above, we are able to identify the moment at which order is reinstated. Brian's final operation once the sign is put in place is worth drawing particular attention to: he begins to clean the sign, which had gradually gotten covered with dust, using a cloth and the sleeve of his sweater. Then, he adds, "Here it is, a brand new sign!" (September 7, 2007, Fieldnotes).

With this seemingly minor gesture, Brian demonstrates dedication to his work as he finishes the long sequence of actions involved in the repair job. But at the same time, there is another action that goes well above and beyond the repair process. His cleaning gesture and associated exclamation literally bring the sign from one state to another. Solidly attached to the wall, stuck to the brackets, free from traces of glue or plaster dust, it becomes an individualized and objectified thing. The damaged object becomes once again a constituent part of the standardized graphical apparatus until a possible future intervention.

Therefore, accounts that insist on the stability or the vulnerability of the Paris wayfinding system are not exclusive. Rather, they stage two versions of the same phenomenon.

Contemporary discussions within material-semiotic studies (Law 2009), or the so-called postANT studies (Gad and Jensen 2010), have shown the importance of exploring the multiplicity of objects and their propensity to enact different realities (Mol 1999, 2002). These studies call into question perspectivism and constructivism, explaining the diversity of reality as the result of material enactments of a multiple world. Differences do not derive from particular standpoints upon a supposed external, singular and intangible reality, but from the multiple performances that contribute to its distinct forms of existence, to its ontological variations. Important, hence, is to examine the ways these different versions are related to one another. Depending on the networks and the practices through which an object is enacted, the 
relationships between its versions may vary considerably ${ }^{3}$. For instance, two versions may be completely separate from one another, they may be contradictory and may even be located in different sites, but they may also temporarily become aligned with one another, be partially connected, added together, or even be included in one another (Law 2010).

In the case of the Paris wayfinding system, what are the links between stabilized and vulnerable versions? Though performed through distinct devices and occupational activities, both versions coexist in the same sites. Moreover, they are strongly relational. The mutations and deteriorations dealt with by the maintenance people throughout their work interventions are identified as such precisely because they are judged on the basis of the designers' standards. The maintenance work consists in repairing damaged signs, replacing those that have faded under the light, updating the information on the signs, and realigning the graphic, linguistic, and material parts according to criteria strictly stabilized in the policy of the wayfinding system. The possibility to enact subway signs as immutable artifacts that perform a material ordering is tied to the workers' ability to handle the "same" subway signs as mutable objects that have to be constantly repaired and replaced. One version is completely dedicated to the other: stability does not emerge via the negation of vulnerability, but rather by its being taken into account. Dealing with their flaws and fragilities, maintenance workers are the signboards' caretakers.

The production of order is thus a process that draws not only on norms and standards, which define stabilized states for objects and their environment, but also on activities accomplished in the name of taking care of things.

\section{The Care of Things}

Maintenance work is a care practice (Tronto 1993; Mol 2008; Puig de la Bellacasa 2010) because it takes into account decay and the vitality of matter (Barad 2003; Bennet 2004; Ingold 2007), instead of denying or relegating these aspects to a secondary dimension. Like care, maintenance work "starts out from the fleshiness and the fragility of life" (Mol 2008, 11). It considers vulnerability as the "natural" state of things and not as a temporary deviation from a healthy normality. In care practices, failures and the fragility of bodies are the mundane conditions of the lives of people and things. Vulnerability is the condition that, moreover, justifies the constant attention that people and things deserve ${ }^{4}$.

An important aspect of maintenance as a care of things is that, since it draws on watchfulness, it cannot be normalized (Orr 1996; Mol, Moser and Pols 2010). Since information about that which is wrong and the point at which something goes wrong cannot be completely obtained in advance, continual adaptation is required. This is partly why maintenance contrasts so starkly with the designers' guidelines. Improvisation is the main fuel of maintenance workers (Henke 2000) whose interventions always overwhelm the

\footnotetext{
3 See notably Singleton and Michael (1993) who have explored the ambivalence of laboratory cytology in a cervical screening program, Mol and Law (1994) who investigated the multiplicity of anemia, or Mol (2002) who detailed versions of artherosclerosis.

${ }^{4}$ Attentiveness is the first of the four phases in the Fisher and Tronto's definition of care (Fisher and Tronto 1990).
} 
standardized procedures (Orr 1996; Edensor 2011). Recognizing this dimension of maintenance work is crucial to the articulation of the two versions discussed previously. The stabilized and vulnerable versions of the subway signs are performed through specific kinds of work and techniques, particular operations and competencies. Maintenance draws on a certain engagement with matter and objects, a bodily commitment, which is at the center of taking care of things.

This commitment has two aspects: the perceptive competencies through which material vulnerabilities are revealed, and the dynamics of assembling and disassembling on which maintenance draws.

\section{A Shared Vision}

What does it mean for maintenance workers to deal with the vulnerability of matter? In which operations is the attention they pay to the fragility of things translated? The answer to these questions emerges upon examining transformations, wear and tear, and deteriorations mentioned previously. These changes, which together bear witness to the fragility of the signs, are not immediately obvious. As observers, or even as mundane subway users, we would not have been able to spot most of these flaws by ourselves. Rather, the maintenance workers were needed to reveal them. Where we saw a series of more or less identical boards, workers immediately distinguished signboards that had wear or symptoms of damage from those in good condition. Above all, where we failed to see anything at all, they were able to diagnose an absence. Yet, there are no precise rules that help maintenance workers to know when a sign has to be changed or repaired. Discovering failures is a situated practice. The maintenance workers drew upon a "skilled vision" (Grasseni 2007), which is at the center of the care of things they perform. Fragility is not a clearly identifiable state of the world with symptoms accessible and visible to everyone. The workers' trained vision is needed to make them appear.

The vulnerable version of the Paris wayfinding system therefore does not depend on the intrinsic and "natural" properties of the signs. It is also not the result of a return to a "real" state, repressed by procedures and guidelines. Like the stabilized version, this version is a performance, enacted with tools and specific techniques (drills, screwdrivers), but also via the very gaze of the maintenance workers. Like most forms of perception, skilled vision is not limited to a single visual capacity and does not mean that only eyesight is engaged. Rather, it depends on movement and relies on gestures that involve the entire body (Gibson 1979).

This attentive vision is grounded in the knowledge maintenance workers progressively acquired about the semiotic network during their daily rounds over the years. Such perceptive competencies are also the result of collective and situated accomplishments that perform what Goodwin (1994) called a "professional vision". While examining and diagnosing the signboards, the maintenance workers observe the boards together, discuss them, take notes and make drawings. They share and continually reiterate operations that articulate forms of seeing, words for description, and material representations.

Skilled vision as a way of paying attention is part of the care of things. Like the logic of care identified by Mol (2002), such a skill is partly distributed. And just as the care of patients is not reserved for doctors and nurses, the capacity to locate faulty signs is not entirely the 
reserve of maintenance workers. This is, at least, what the maintenance workers strive to make the case, for they by no means consider their perceptive competencies as their exclusive domain. In fact, they regularly try to make others sensitive to the vulnerabilities of signboards and to the necessity of taking care of them. This is particularly the case of station superintendents, who are supposed to report anomalies when opening their stations, but in the eyes of maintenance workers do not get involved enough. During our observations, we witnessed several harsh discussions between maintenance operators and superintendents about reports that they did not find detailed enough, and even about boards that should have been identified as faulty but were not. The maintenance workers regularly remind the superintendents of the importance of paying attention to the boards. Sometimes the workers indicate certain signboards in particular, showing the managers the subtle material transformations that have taken place. Doing so, they share with them some aspects of their skilled vision, trying to widen the care for signboards to other employees.

This distribution of care is nevertheless minimal in regards to the care Mol (2002) shed light upon, since it does not include riders. Maintenance work seems to be entirely centered on the importance of intervening before the riders are able to become aware of the vulnerability of the objects making up the wayfinding system. Hence, it performs a boundary - not selfevident and not always efficient - between an occupational community with a skilled vision of sign vulnerability and the subway users, meant to see the wayfinding system as one of order and stability.

\section{Dis/assemblages}

As we have seen, a large part of the maintenance workers' task consists of producing and reproducing material and semiotic assemblages. The appeal of studying the concrete operations of repair and maintenance lies therein, since these operations reveal assemblages that are not merely describable, inert results, but rather actions in the making. In caring for their signs, the maintenance workers attempt to hold the assemblage of the wayfinding system together. However, in observing the workers in practice, it becomes clear that this is not the only aspect of their work: taking care of signs also means regularly disassembling and dismantling them. In the course of an intervention, a sign can switch in a few minutes from an electric board to a pile of screws next to a plastic sheet and a transparent display. What was present in situation as a simple artifact suddenly turns into a list of various materials. Disassemblage is thus just as important as assemblage in the care of things, and the dynamics between the two are essential to maintenance. As repaired and maintained objects, signboards can change from one mode of existence to another in both directions: from a unified entity to scattered heterogeneous parts, and back to a consolidated artifact. These changes never occur at the same time, they are essential steps in what we could term, following Pickering (1995), the "dance" of maintenance.

Another important aspect of disassemblage deals with the care of things in its totality. The dismantling operations do not only require that workers have the necessary skills to complete them (Dant 2010; Gregson et al. 2009), but also that the objects themselves have certain properties (DeLanda 2006). In order to be dismantled, objects must be dismantle-able. But in this respect, objects are far from equal. The question of planned obsolescence, which has 
emerged in the past several years as a major public issue, points to this aspect. Certain devices no longer function or lack the capacity to be dismantled, creating real scandals and affairs. Like maintenance, "maintainability" has become a central concern in models for sustainable development (Graham and Thrift 2007), most notably opening the way up for new forms of innovation (de Laet and Mol 2000).

In our case, the capacity of objects to be maintained easily creates problems that are summarized by an explanation given by two maintenance workers after having encountered a particularly stubborn signboard:

This makes no sense, 16 screws just to get at this panel. All we'd need is a little trap along here and we could easily get the sign out without even having to open the box up, without needing to take anything out... But they don't think about that. They don't think about us. (Jonathan to the ethnographer during an intervention, July 4, 2007, Fieldnotes).

Maintainability directly raises the issue of the concrete conditions of the care of things. In dealing with the ability of things to be taken care of, the question of maintainability first highlights the physical difficulties the maintenance workers may encounter during disassembling operations. The less maintainable the object is, the harder the bodily commitment is. Maintainability issues also pave the way for a discussion of the relationship between the two versions we have highlighted in this article. Reinforcing maintainability indeed would end up balancing out the relationship of dependency between the stabilized version and the vulnerable one: to the first would be added an awareness of the second. For now though, the vulnerable version, enacted by maintenance work, is entirely oriented toward the success of the stabilized version. This relationship bears witness to a sequential process wherein the designers' version prevails and constantly frames the work of the maintenance employees.

Maintenance and design have here consonant goals: The two subway signs versions and the practices that enact them are both oriented toward consistency and sturdiness. Designers have invested in signs' material and semiotic standardization to shape a homogeneous and stabilized environment, which focused design on the capacity for signs to last and remain unchanged. Inscribing maintainability as a matter of concern in designers' work would simply mean reconsidering stability, and accepting that material ordering is not the performance of the material properties of signs only. Signs could be designed with a stronger consideration for repair and maintenance practices, assuming broader sociotechnical solidarity for material ordering and emphasizing openness instead of closure ${ }^{5}$. In the terms of care, thus, a concern for maintainability translates material permanency into sociotechnical sustainability, and recognizes that stability, like reality, is "an active verb" (Haraway 2003, 6).

\section{Conclusion}

In studying designers' stabilization work during the installation of a new signage policy together with the operations of maintenance workers, we have shown that the material

\footnotetext{
${ }^{5}$ We are grateful to one of the anonymous reviewers who drew our attention to these questions and suggested we specify this point.
} 
ordering performed by subway signs engages two versions of objects: a stabilized one, which lies on standards and detailed guidelines, and a vulnerable one, which is enacted in repair and maintenance practices. Whereas the first version has been largely discussed in STS, the second one remains overlooked6.

In this, our position is different from Ingold's (2007) diatribe against material culture studies. Our objective is not to defend a vulnerable, composite, and heterogeneous definition of objects against a conception that would stress stability and durability. Rather, we wish to recognize the coexistence of these two versions, enacted in distinct situations and through different practices. Our study can be seen as complementary to de Laet and Mol's (2000), which discusses maintenance from the vantage point of innovation. de Laet and Mol showed that certain technical objects remain open to modification and disassemblage as they develop. They present maintenance as a rarely studied mode of existence of objects, but also, and above all, as an alternative form of innovation, contrasting with those already described in STS (namely the stabilization of ANT's black boxes, or the gradual closure of social construction of technology). In this article, we have shown that these forms may coexist. Certain maintenance practices are not oriented toward object transformation and modification, but rather toward restoration: that is, the continuation of their being immutable. Maintenance work, in this case, tends toward order and stability, fueling them on a daily basis.

This posture and the findings that resulted have both methodological and political grounds and implications. Following maintenance workers during their daily rounds, after studying designers' work, contrasts with the usual points of entry of innovation studies, which generally draw a two-sided landscape made of users and designers (Jackson 2014). The ethnography of maintenance foregrounds improvisations, attentiveness, and the diversity of the material ecology that underpins an apparently stable environment designed for users' comfort. But such a gesture does not only invites one to reconsider the human competencies "behind" a technical or semiotic network. It also implies rethinking objects themselves and the way we deal with them. Accompanying the subway signs maintenance workers, we progressively learned to see and treat the signs the way they did: fragile and mutating entities, the boundaries of which were sometimes blurred; things that have to be taken care of, despite their standardized design and despite their ordering aims. Maintenance practices and concerns enact objects as vulnerable entities. As a care of things, it also performs order in a very particular manner, where flaws and breakdowns are not a series of breaches in a preexisting higher order, but basis for a ceaselessly enacted order.

Therefore, our study contributes to the recent pleas for a nonnormative definition of care (Mol, Mozer and Pols 2010; Puig de la Bellacasa 2012). Above all, foregrounding the vulnerable version of the Paris wayfinding system (in contrast with the stabilized one) is a politics of knowledge (Puig de la Bellacasa 2010). Indeed, in looking to identify certain

\footnotetext{
6 Along Graham and Thrift (2007), a few scholars are directly interested in maintenance in STS, particularly in infrastructure studies. Baker and Bowker (2007) notably insist on the importance of databases maintenance and "data care", which imply invisible costs in long-term projects. Recently, Jackson (2014) also made a plea for "rethinking repair" and reconsidering breakdowns in media studies.
} 
aspects of the care of things that take place during maintenance processes, we do not claim to have adopted an outside point of view that would reveal, neutrally and detachedly, a previously overlooked reality. Our research must be understood as a form of care applied to the material care practices of maintenance workers, who are largely neglected in the official narratives of Paris wayfinding system, and to the subway signs themselves, which are not just inert standardized objects.

Beyond the little social and scientific attention that has been paid to maintenance processes (Graham and Thrift 2007), certain situations tend to delete the material vulnerability of things as well as the work linked to them. Star (1991) showed that some managerial models favor principles and tools that turn part of professional activity into "silenced work." Suchman (2007) identified a similar type of effacement with regards to certain innovations founded on artificial intelligence models that neglect the complex adjustments of situated action. In the same way, the production of objects and standardized apparatuses that establish a seemingly self-evident sociomaterial order tends to have its maintenance operations masked, removed from the experience of users. This relational invisibility (Star and Strauss 1999) of maintenance work has an important impact not just on the work conditions of the maintenance employees, but also on the objects' very mode of existence. Demonstrating that the care of things is important - including the things that appear to be the most solid and stable - brings to the surface the work that underlies the production of sociomaterial order, while acknowledging the vulnerability of things and the importance of their maintainability: that is, their capacity to be taken care of.

\section{Acknowledgments}

The authors are very grateful to Blanca Cállen for her thoughtful comments, to their colleagues of the Centre de Sociologie de I'Innovation, and the two anonymous reviewers for their very helpful suggestions on a previous version of this article, and to Jill McCoy for her professional commitment in the translation process. This article is based on a research that was part of the 'Écologies et Politiques de l'Écrit' program, funded by the National Agency for Research in France (ANR-05-BLAN-0272-02).

\section{Sources}

RATP. 1997. Signalétique multimodale. La RATP fait signe aux voyageurs, Document de présentation interne, Département des projets, Conception de l'information.

RATP. 2007a. Guide "Information Voyageurs "Dénomination des gares, stations et arrêts", Délégation Générale Espaces de Transports et Intermodalité.

RATP. 2007b. Norme "Information Voyageurs. Signalétique multimodale", 3 volumes, Délégation Générale Espaces de Transports et Intermodalité.

Wiart, A., Le Roux, A. and Lomazzi, M. 1998. "Signalétique, le nouveau fil d'ariane." La Vie du Rail et des Transports, 57: 30-35. 


\section{References}

Appadurai, A. 1986. The Social Life of Things: Commodities in Cultural Perspective. Cambridge: Cambridge University Press.

Barad, K. 2003. "Posthumanist Performativity: Toward an Understanding of How Matter Comes to Matter." Signs: Journal of Women in Culture and Society 28 (3): 801-831.

Bennett, J. 2004. "The Force of Things: Steps Toward an Ecology of Matter." Political Theory 32 (3): 347-372.

Baker, K., and G. Bowker. 2007. "Information ecology: open system environment for data, memories, and knowing." Journal of Intelligent Information Systems 29 (1): 127-144.

Brand, S. 1994. How Buildings Learn: What Happens After They're Built. Penguin Books: London.

Dant, T. 2010. "The Work of Repair: Gesture, Emotion and Sensual Knowledge." Sociological Research Online 15 (3).

de Laet, M., and A. Mol. 2000. "The Zimbabwe Bush Pump: Mechanics of a Fluid Technology." Social Studies of Science 30 (2): 225-263.

DeLanda, M. 2006. A New Philosophy of Society. Assemblage Theory And Social Complexity. London: Continuum.

Denis, J., and D. Pontille. 2010a. Petite sociologie de la signalétique. Les coulisses des panneaux du métro. Paris: Presses des Mines ParisTech.

Denis, J., and D. Pontille, 2010b. "Placing Subway Signs: Practical Properties of Signs at Work." Visual Studies 9 (7): 441-462.

Denis, J., and D. Pontille. 2010c. "The Graphical Performation of a Public Space. The Subway Signs and Their Scripts." In Urban Plots, Organizing Cities, edited by Giovanna Sonda, Claudio Coletta, and Francesco Gabbi, 11-22. London: Ashgate.

Dewey, J. "Logic: The Theory of Inquiry." In John Dewey: The Later Works, 1925-1953, Vol. 12, edited by J.A. Boydston. Carbondale, IL: SIU Press.

Edensor, T. 2011. "Entangled Agencies, Material Networks and Repair in a Building Assemblage: The Mutable Stone of St Ann's Church." Transactions of the Institute of British Geographers 36 (2): 238-252.

Eisenstein, E. L. 1983. The Printing Revolution in Early Modern Europe. Cambridge: Cambridge University Press.

Engestrom, Y., and F. Blackler. 2005. "On the Life of the Object." Organization 12 (3): 307330.

Farías, I., and T. Bender, ed. 2010. Urban Assemblages: How Actor-Network Theory Changes Urban Studies. London / New York: Routledge.

Fisher, B., and J. Tronto. 1990. "Toward a feminist theory of caring." In Circles of care: Work and identity in women's lives, edited by Emily K. Abel and Margaret K. Nelson, 35-62. Albany: SUNY Press.

Fuller, G. 2002. "The Arrow - Directional Semiotics: Wayfinding in Transit." Social Semiotics 12 (3): 231-244.

Gad, C., and C. Bruun Jensen. 2009. "On the Consequences of Post-ANT." Science, Technology \& Human Values 35 (1): 55-80.

Gibson, J. J. 1979. The Ecological Approach to Visual Perception. Boston: Houghton Mifflin.

Goffman, E. 1971. Relations in Public: Microstudies of the Public Order. New York: Basic Books. 
Goodwin, C. 1994. "Professional Vision." American Anthropologist 96 (3): 606-633.

Goody, J., M. Cole, and S. Scribner. 1977. "Writing and Formal Operations: a Case Study Among Vai." Africa 47 (3): 289-304.

Graham, S., and N. Thrift. 2007. "Out of Order: Understanding Repair and Maintenance." Theory, Culture \& Society 24 (3): 1-25.

Grasseni, C. 2007. "Skilled Vision. An Apprenticeship in Breeding Aesthetics." Social Anthropology 12 (1): 41-55.

Gregson, N., A. Metcalfe, and L. Crewe. 2009. "Practices of Object Maintenance and Repair: How Consumers Attend to Consumer Objects Within the Home." Journal of Consumer Culture 9 (2): 248-272.

Haraway, D. J. 2003. The Companion Species Manifesto: Dogs, People, and Significant Otherness. Chicago: Prickly Paradigm Press.

Henke, C. R. 2000. "The Mechanics of Workplace Order: Toward a Sociology of Repair." Berkeley Journal of Sociology 44: 55-81.

Ingold, T. 2007. "Materials Against Materiality." Archaeological Dialogues 14 (01): 1-16.

Jackson, S. J. 2014. "Rethinking Repair." In Media Technologies: Essays on Communication, Materiality and Society, edited by Tarleton Gillespie, Pablo Boczkowski, \& Kirsten Foot, 221240. Cambridge, MA: MIT Press.

Joseph, Isaac. 2004. Météor. Les Métamorphoses Du Métro. Paris: Economica.

Knorr-Cetina, K. 1997. "Sociality with Objects: Social Relations in Postsocial Knowledge Societies." Theory, Culture \& Society 14 (4): 1-30.

Knox, H., D. O'Doherty, T. Vurdubakis, and C. Westrup. 2008. "Enacting Airports: Space, Movement and Modes of Ordering." Organization 15 (6): 869-888.

Kripke, S. 1980. Naming and Necessity. Cambridge, Mass.: Harvard University Press.

Latour, B. 1986. "Visualisation and Cognition: Drawing Things Together." Knowledge and Society: Studies in the Sociology of Culture and Present 6: 1-40.

Latour, B. 1996. "On Interobjectivity." Mind, Culture and Activity 3 (4): 228-245.

Latour, B., and E. Hermant. 1998. Paris Ville Invisible. Paris: La Découverte / Les Empêcheurs de penser en rond.

Latour, B., and S. Woolgar. 1986. Laboratory Life: The Social Construction of Scientific Facts. Princeton, N.J.: Princeton University Press.

Law, J. 2004. After Method: Mess in Social Science Research. London / New York: Routledge.

Law, J. 2009. "Actor Network Theory and Material Semiotics." In The New Blackwell Companion to Social Theory, edited by Bryan S. Turner, 141-158. Oxford: Wiley-Blackwell.

Law, J. 2010. "The Materials of STS." In The Oxford Handbook of Material Culture Studies, edited by Dan Hicks and Mary Beaudry, 173-188. Oxford: Oxford University Press.

Law, J., and J. Hassard, ed. 1999. Actor Network Theory and After. Oxford: Blackwell Publishing.

Leonardi, P., and S. Barley. 2008. "Materiality and Change: Challenges to Building Better Theory About Technology and Organizing." Information and Organization 18 (3): 159-176.

McFarlane, C. 2011. "The City as Assemblage: Dwelling and Urban Space." Environment and Planning D: Society and Space 29 (4): 649-671. 
Mol, A. 1999. "Ontological Politics. A Word And Some Questions." In Actor Network Theory and After, edited by John Law and John Hassard, 74-89. Oxford: Blackwell Publishers.

Mol, A. 2002. The Body Multiple: Ontology in Medical Practice. Durham: Duke University Press.

Mol, A. 2008. The Logic of Care: Health and the Problem of Patient Choice. New York: Routledge.

Mol, A., and J. Law. 1994. "Regions, Networks and Fluids: Anaemia and Social Topology." Social Studies of Science 24 (4): 641-671.

Mol, A., I. Moser, and J. Pols, ed. 2010. Care in Practice. On Tinkering in Clinics, Homes and Farms. London: Transcript.

Orlikowski, W. J. 2007. "Sociomaterial Practices: Exploring Technology at Work." Organization Studies 28 (9): 1435-1448.

Orr, J. E. 1996. Talking About Machines: An Ethnography of a Modern Job. New York: Cornell University Press.

Pels, D., K. Hetherington, and F. Vandenberghe. 2002. "The Status of the Object. Performances, Mediations, and Techniques." Theory, Culture \& Society 19 (5/6): 1-21.

Petrucci, A. 1993. Public Lettering. Script, Power, and Culture. Chicago: The University of Chicago Press.

Pickering, A. 1995. The Mangle of Practice: Time, Agency, and Science. Chicago: The University of Chicago Press.

Puig de la Bellacasa, M. 2010. "Matters of Care in Technoscience: Assembling Neglected Things." Social Studies of Science 41 (1): 85-106.

Puig de la Bellacasa, M. 2012. “Nothing comes without its world': thinking with care." The Sociological Review 60 (2): 197-216.

Sharrock, W. W., and D. C. Anderson. 1979. "Directional Hospital Signs as Sociological Data." Information Design Journal 1 (2): 81-94.

Singleton, V., and M. Michael. 1993. "Actor-Networks and Ambivalence: General Practitioners in the UK Cervical Screening Programme." Social Studies of Science 23 (2): 227-264.

Star, S. L., ed. 1995. Ecologies of Knowledge. Work and Politics in Science and Technology. Albany, NY: SUNY Press.

Star, S. L., and K. Ruhleder. 1996. "Steps Toward an Ecology of Infrastructure: Design and Access for Large Information Spaces." Information Systems Research 7 (1): 111-134.

Star, S. L., and A. Strauss. 1999. "Layers of Silence, Arenas of Voice: The Ecology of Visible and Invisible Work." Computer Supported Cooperative Work 8 (1-2): 9-30.

Strauss, A. 1978. Negotiations: Varieties, Processes, Contexts, and Social Order. San Francisco: Jossey-Bass Inc.

Suchman, L. A. 2011. "Lecture Practice and Its Overflows: Reflections on Order and Mess." Tecnoscienza 2 (1): 21-30.

Suchman, L. A. 2007. Human-Machine Reconfigurations. Plans and Situated Actions, 2nd Edition. Cambridge: Cambridge University Press.

Thompson, M. 1979. Rubbish Theory: The Creation and Destruction of Value. Oxford: Oxford Univeristy Press.

Timpf, S. 2002. "Ontologies of Wayfinding : a Traveler's Perspective." Networks and Spatial Economics 2 (1): 9-33. 
Tronto, J. 1993. Moral Boundaries: A Political Argument for an Ethic of Care. New York: Routledge.

Ureta, S. 2013. "Waiting for the Barbarians: Disciplinary Devices on Metro de Santiago." Organization 20 (4): 596-614.

Urry, J. 2007. Mobilities. Cambridge: Polity Press.

Verbeek, P. P. 2004. What Things Do: Philosophical Reflections on Technology, Agency and Design. University Park: Pennsylvannia State University Press.

Vertesi, J. 2008. "Mind the Gap: The London Underground Map and Users' Representations of Urban Space." Social Studies of Science 38 (1): 7-33.

Weisman, A. 2007. The World Without Us. London: Virgin.

Winner, L. 1980. "Do Artifacts Have Politics?" Daedalus 109 (1): 121-136. 